\title{
Urticaria and Angioedema Associated with Fluoxetine
}

\author{
Taha Can Tuman ${ }^{1}$, Bengü Tuman ${ }^{2}$, Mualla Polat ${ }^{2}$, Uğur Çakır ${ }^{3}$ \\ ${ }^{1}$ Izzet Baysal Teaching and State Hospital for Psychiatry, Departments of ${ }^{2}$ Dermatology and ${ }^{3}$ Psychiatry, Faculty of Medicine, Abant İzzet Baysal \\ University, Bolu, Turkey
}

\section{TO THE EDITOR}

Fluoxetine is well tolerated and generally used to treat depression, anxiety and obsessive compulsive disorders. Fluoxetine is the first selective serotonin reuptake inhibitor (SSRI) that was used in the treatment of mental disorders. ${ }^{1)}$ The most common side effects reported with fluoxetine involve gastrointestinal problems, insomnia, agitation, dizziness, tremor, headache and sexual dysfunction. ${ }^{2)}$ Urticaria is edema of superficial dermis and characterized by erythematous, often pruritic, elevated papules and plaques. If edema also spread into deep dermis called angioedema. ${ }^{3)}$ While the duration of the urticaria and angioedema is less than six weeks, it is termed acute urticaria. Acute urticaria can often be associated with a spesific cause or trigger. The most common cause of acute urticaria and angioedema is enfections and drugs. ${ }^{4)}$ Here, we report an adult patient who developed acute urticaria and angioedema during treatment with fluoxetine.

Twenty three year old boy was admitted to our outpatient unit with complaints of anhedonia, malaise, fatigue, weakness, reduced concentration and hypersomnia. His physical and laboratory examination (complete blood count, thyroid function, B12 and folate tests) were normal. The patient received 18 points in the Hamilton Rating Scale for Depression. Fluoxetine $20 \mathrm{mg}$ per day treatment was started to the patient with a diagnosis of major depression according to the Diagnostic and Statistical Manual of Mental Disorders 5th edition. The second week of the treatment, the patient was admitted to the dermatology outpatient unit with complaints of generalized pruritus and swelling in periorbital area. On dermatological ex-

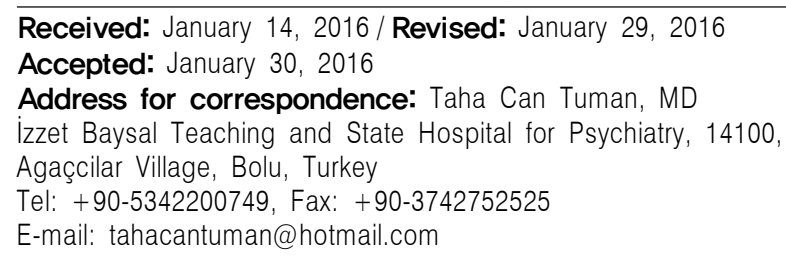

amination generalized urticarial plaques, periorbital edema, swelling of the lips and diffuse erythema was observed. The patient was hospitalized to the dermatology inpatient unit with a diagnosis of urticaria and angioedema. There was no evidence of urticaria and angioedema in medical and family history of the patient. There was no history of food and drug allergy. Fever, cough, vomiting, rhinorrhea, headache, diarrhea as indicators of recent illness did not accompany to the patients symptoms and signs. Insect bite, sun or cold exposure, exercise, exposure to intravenous radiocontrast agents, new perfumes, lotions, cremes, chemicals and use of any other medication and food supplements were excluded for differantial diagnosis. His laboratory examination (complete blood count, renal function tests, thyroid function tests, electrolites, hepatic function tests, urinalysis, erythrocyte sedimantation rate, C-reactive protein) was normal. Naranjo Adverse Drug Reaction Probability Scale was evaluated as 6 points, a manuscript probable adverse effect associated with fluoxetine. ${ }^{5)}$ The diagnosis was compatible with fluoxetine associated urticaria and angioedema. Fluoxetine was stopped. The patient was started on intravenous methylprednisolone and antihistamines. The signs and symptoms remitted completely within 96 hours of treatment and the patient discharged from dermatology inpatient unit to be followed up as outpatient. There were no complaints of patient on outpatient control examination after two weeks of discharge. The patient was started on sertraline treatment for his depression and at the one year of the treatment any side effect was observed.

Here, we reported a case of acute urticaria and angioedema, in a Turkish adult with major depressive disorder, that was thought to be associated with fluoxetine. In clinical trials, $7 \%$ of the patients reported to develop rashes and/or urticaria. Most of patients improved with cessation of fluoxetine and/or adjunctive antihistamines or steroids. ${ }^{6)}$ When we put the diagnosis of urticaria and angioedema, we stopped fluoxetine and started to steroid

(c) This is an Open-Access article distributed under the terms of the Creative Commons Attribution Non-Commercial License (http://creativecommons.org/licenses/by-nc/4.0) which permits unrestricted non-commercial use, distribution, and reproduction in any medium, provided the original work is properly cited. 
and antihistamine therapy to the patient. Until now, there has been only one report of urticaria and angioedema associated with fluoxetine in adults, which was thought to be the result of overdose. ${ }^{7)}$ In child and adolescent psychiatry literature, there has been also one report of angioedema related to fluoxetine in a preadolescent. ${ }^{8)}$ Our case is the first in that the urticaria and angioedema developed with therapeutic doses. The mechanism of acute urticaria and angioedema associated with fluoxetine is unclear. ${ }^{8)}$ In our case, increased serotonin concentration caused by fluoxetine may play a role in the development of acute urticaria and angioedema. In literature, sumatriptan, paroxetine and other SSRIs were reported to cause angioedema. ${ }^{9-11)}$ In some individuals that sensitive to rapid changes of peripheral serotonin concentration, chocolate and other foods may cause adverse reactions during SSRI therapy. ${ }^{12)}$ The second explanation is that drug molecules may interact in a labile and non covalent way with $\mathrm{T}$ cell receptors and possibly with major histocompatibility molecules to activate immune system and steer inflammatory cells toward the dermiş. ${ }^{13)}$ Fluoxetine is an effective choice and one of the most commonly used SSRIs in psychiatry units. Clinicians should investigate the use of SSRIs in patients with urticaria and angioedema and be cautious of the dermatologic adverse reactions of fluoxetine at the time of prescribing. Because this side effect may sometimes be life-threatening. Our findings must be supported by further studies. New studies may contribute to understand the mechanism of fluoxetine associated urticaria and angioedema.

\section{REFERENCES}

1. Perez-Caballero L, Torres-Sanchez S, Bravo L, Mico JA, Berrocoso E. Fluoxetine: a case history of its discovery and preclinical development. Expert Opin Drug Discov 2014;9: 567-578.

2. Cole JO, Bodkin JA. Antidepressant drug side effects. J Clin Psychiatry 1990;51 Suppl:21-26.

3. Kaplan AP. Urticaria and angioedema. In: Adkinson Jr NF, editor. Middleton's allergy: Principles and practice. Philadelphia (PA):Mosby;2009. p.1061-1081.

4. Zuberbier T, Maurer M. Urticaria: current opinions about etiology, diagnosis and therapy. Acta Derm Venereol 2007; 87:196-205.

5. Naranjo CA, Busto U, Sellers EM, Sandor P, Ruiz I, Roberts EA, et al. A method for estimating the probability of adverse drug reactions. Clin Pharmacol Ther 1981;30:239-245.

6. Lilly USA, LLC. Prozac; manufacturer insert [Internet]. Indianapolis (IN): Lilly USA, LLC.; 2014 Oct 10 [cited at 2015 Oct 18]. Available from: http://pi.lilly.com/us/prozac. $p d f$.

7. Kim SW, Pentel PR. Flu-like symptoms associated with fluoxetine overdose: a case report. J Toxicol Clin Toxicol 1989;27:389-393.

8. Tuman TC, Demir N, Topal Z, Tuman BA, Tufan EA. Angioedema probably related to fluoxetine in a preadolescent being followed up for major depressive disorder. J Child Adolesc Psychopharmacol 2013;23:697-698.

9. Mithani H, Hurwitz TA. Paroxetine-induced angioedema and tongue swelling. J Clin Psychiatry 1996;57:486.

10. Dachs R, Vitillo J. Angioedema associated with sumatriptan administration. Am J Med 1995;99:684-685.

11. Krasowska D, Szymanek M, Schwartz RA, Myśliński W. Cutaneous effects of the most commonly used antidepressant medication, the selective serotonin reuptake inhibitors. $J$ Am Acad Dermatol 2007;56:848-853.

12. Cederberg J, Knight S, Svenson S, Melhus H. Itch and skin rash from chocolate during fluoxetine and sertraline treatment: case report. BMC Psychiatry 2004;4:36.

13. Hausmann O, Schnyder B, Pichler WJ. Drug hypersensitivity reactions involving skin. Handb Exp Pharmacol 2010;(196): $29-55$. 